\title{
Three new species of Cephalobium (Nematoda, Cephalobiidae) parasites of Gryllodes laplatae (Orthoptera, Gryllidae) from Argentina
}

\author{
Nora B. Camino \& Guillermo R. Reboredo
}

\author{
Centro de Estudios Parasitológicos y de Vectores, CEPAVE, Calle 2, 584, 1900 La Plata, Argentina. Investigador CIC. \\ (cepave@ cepave.com.ar)
}

\begin{abstract}
Three new species of Cephalobium Cobb, 1920, C. laplata from City Bell, C. polidentatum from Lincoln and C. dispar from Gorina, parasites of Gryllodes laplatae Saussure, 1877 from Buenos Aires, Argentina, are described and illustrated. Cephalobium laplata can be differentiated by having the cheilostom with a dorsal unmovable tooth, telostom with three ventral little teeth and two ventral movable claw teeth and gubernaculum triangular and five pairs of genital papillae. Cephalobium polidentatum has cheilostom with a movable ventral tooth, prostom with four dorsal movable teeth and telostom with three teeth; gubernaculum triangular with projections and with one pair of preanal and six pairs of postanal papillae. Cephalobium dispar is characterized by having telostom with two wings around the spicules and one pair of preanal and six pairs postanal papillae.
\end{abstract}

KEYWORDS. Cephalobiidae, Cephalobium, Gryllidae, parasites, taxonomy.

\section{INTRODUCTION}

The genus Cephalobium was established by Совв (1920), with the type species C. microbivorum from crickets from North America. ARTigas (1929) described C. nitidum from mole crickets from Brazil. RAO \& RAO (1965) proposed C. microvata, a parasite of crickets from India. Spiridonov \& VAn Luc (1994) described $C$. montanum, from crickets in Vietnam. CAMINO \& REBOREDO (2000) described C. bidentatum, a parasite of crickets from Argentina.

Three new species of Cephalobium are described: C. laplata, C. polidentatum and C. dispar, all obligate parasites of the intestine of Gryllodes laplatae Saussure, 1877 from Argentina.

\section{MATERIAL AND METHODS}

Adults of Gryllodes laplatae found in City Bell $(\mathrm{n}=25)$, Gorina $(\mathrm{n}=38)$ (Department of La Plata), and Lincoln $(n=28)$ (Department of Lincoln), province of Buenos Aires, Argentina, were manually collected. The crickets were identified in SAUSSURE (1877). In the laboratory, following techniques of POINAR (1975), the insects were put to sleep at $5^{\circ} \mathrm{C}$ during $10 \mathrm{~min}$, and then were dissected in Petri dishes with distilled water under microscope stereoscope. The nematodes found in the intestine of the insects were killed in distilled water at $60^{\circ} \mathrm{C}$, immersed in a solution of distilled water + TAF during $48 \mathrm{~h}$ (1:1) and fixed in pure TAF. Living and fixed specimens were used for drawing and measurements using a camera lucida microscope, and a micrometer in a compound microscope. Measurements in micrometers are given for holotype and allotype; for paratypes the range is in parenthesis. Holotype and allotype are deposited in the Helminthological collection of Museum La Plata (MLP), paratypes deposited in Centro de Estudios Parasitológicos y de Vectores Helminthological collection (CHC).
Cephalobium laplata sp. nov.

(Figs. 1-7)

Description. Lip ring divided by grooves into six ribs. Stoma longer than broad. Glottoid apparatus anisoglottid and anisomorphic. Cheilostom with dorsal unmovable tooth, protostom cuticularized and telostom with three ventral small teeth and two ventral movable claw teeth, these two teeth project well into lumen of stoma (figs. 1, 7). Oesophagus long, with pseudobulb valved, short isthmus and basal bulb not valved, which comes into anterior end of intestine (figs. 1,2). Excretory pore opened at level of isthmus. Vulva median and not protruding, vagina short and cylindrical, gonads paired (fig. 5). Male with two spicules, separated, with hookshaped tip, gubernaculum triangular (fig. 6). Five pairs of postanal genital papillae (fig. 4): one pair behind anus, three pairs grouped, one pair at base of tail. Bursa absent. Tail in both sexes subulated (fig. 3 ).

Male $(\mathrm{n}=18)$ : body length, $3,150(2,940-3,360)$; width of head at level of lip ring, 19.9 (18.8-21.1); stoma length, 32.9 (31.5-33.1), width, 7 (6.9-7.3); distance from anterior end to pseudobulb, 332.5 (310.2-354.8), to base of bulb, 424.2 (392.9-455.9), to excretory pore, 367.8 (336399.5), greatest width of body, 85.8 (79.9-91.6), width of body at level of anus, 63.4 (61.1-65.8), spicules length, 70.5 (61.1-79.9), gubernaculum length, 36.4 (35.2-37.6), tail length, 61.1 (58.3-63.5).

Female $(\mathrm{n}=23)$ : body length, $3,800(3,480-4,120)$, width of head at level of lip ring, 22.9 (22.3-23.5), stoma length, 34.6 (34-35.2), width, 9.9 (8.2-11.7), distance from anterior end to pseudobulb, 307.8 (300.8-314.9), to base of bulb, 419.5 (404.2-434.7), to excretory pore, 347.8 (345.3349.8), greatest width of body, 130.4 (105.7-155.1), width of body at level of vulva, 132.2 (105.8-155.5), $\mathrm{V}, 44.6 \%$ (42.9-46.3), length and width of eggs, 72.8 (72.2-72.9) $\mathrm{x}$ $42.3(39.9-44.6)$. 


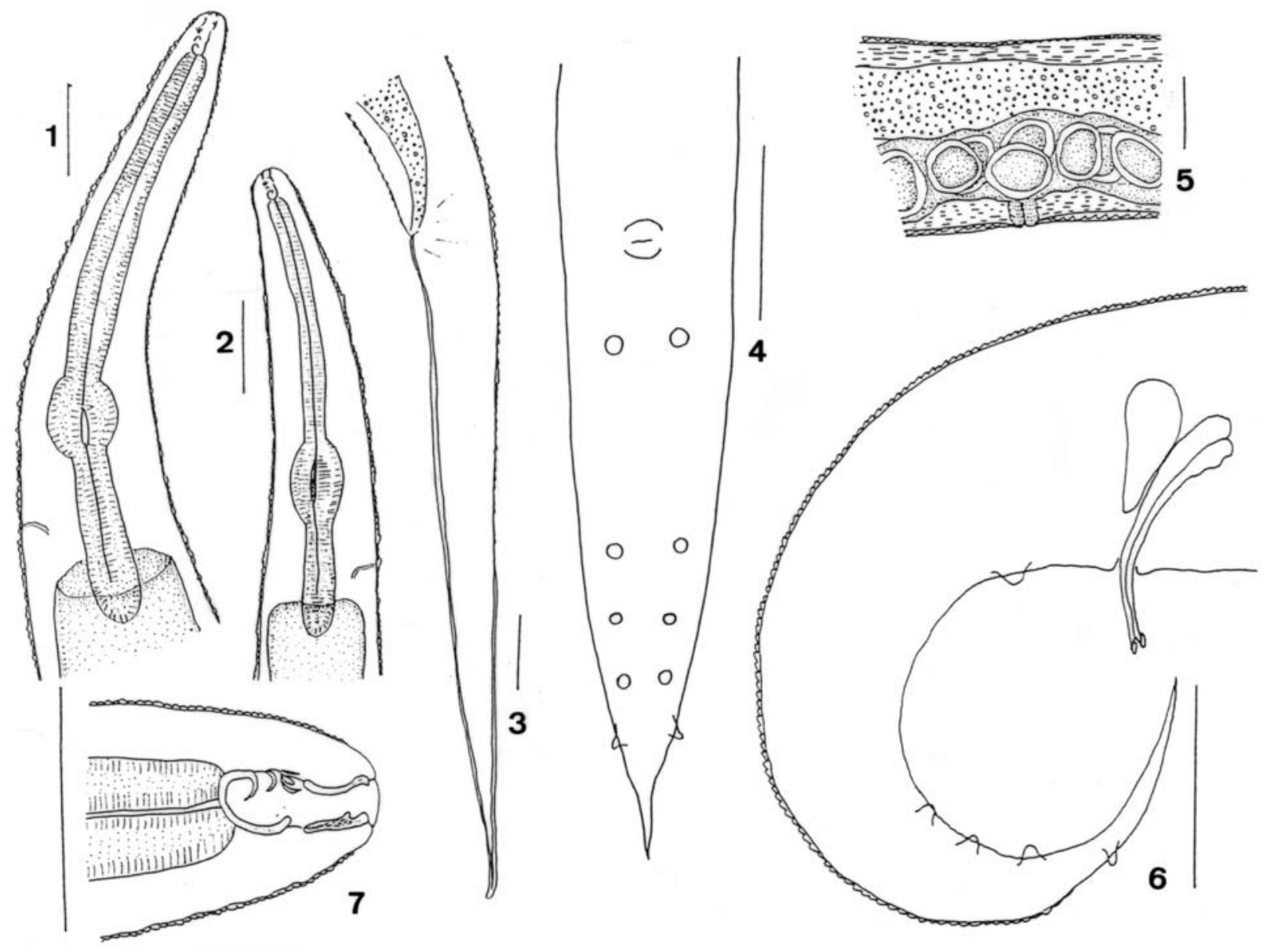

Fig. 1-7. Cephalobium laplata sp. nov: 1, anterior end of female, ventral view; 2, anterior end of male, ventral; 3 , posterior end of female, lateral; 4, posterior end of male, ventral; 5, vagina and uteri with eggs; 6, posterior end of male, lateral; 7, stoma. Bars $50 \mu \mathrm{m}$.

Type host. Adults of Gryllodes laplatae Saussure, 1877 (Orthoptera, Grillidae).

Type material: ${ }^{\top}$ holotype,, allotype, ARGENTINA, Buenos Aires: La Plata, City Bell, horticulture field (MLP 5071); paratypes same locality, 17 ๙, 22 \%, VII-XII.1999, Reboredo-Camino col. (CHC 267-269).

\section{Cephalobium polidentatum sp. nov. (Figs. 8-14)}

Description. Six lips papillae around the mouth. Stoma longer than broad. Glottoid apparatus anisomorphic. Cheilostom with a moveable ventral tooth, protostom has a ventral portion very cuticularized and dorsal one with four movable teeth; telostom with three teeth projected into the lumen of the stoma (fig. 14). Oesophagus long, pseudobulb has a valve, isthmus and basal bulb without valve, the basal bulb the anterior end of intestine (figs. 8, 9). Excretory pore at the level of pseudobulb. Vulva median and not protruding. Vagina short and strong, gonads paired (fig. 12). Male with two spicules, paired, slightly curved, with hook-shaped tips, gubernaculum triangular with two pointed projections (fig. 13). Seven pairs of genital papillae (fig. 11), one pair of preanal papillae and six pairs of postanal papillae which one near the anus, four pairs grouped, one pair at the base of the tail. Bursa absent. Tail in both sexes thin and pointed (fig. 10).

Male $(\mathrm{n}=20)$ : body length, 3,000 $(2,580-3,420)$; head width at level of lip ring, 19.9 (18.5-21.2); stoma length, 31.7 (30.5-32.9), width, 8.2 (7-9.4); distance from anterior end to pseudobulb, 325.5 (317.2-333.7), to base of bulb, 410 (385.4-434.7), to excretory pore, 287.7 (270.2-305.5); greatest width of body, 104.6 (98.7-110.4); width of body at level of anus, 76.4 (70.5-82.2); spicules length, 71.7 (68.1-75.2); gubernaculum length, 47 (42.3-51.7); tail length, 65.5 (59.6-68.7).

Female $(\mathrm{n}=22)$ : body length, $3,890(3,860-3,920)$; width of head at level of lip ring, 19.9 (16.4-23.5); stoma length, 36.4 (35.2-37.6), width, 10.6 (9.4-11.7); distance from anterior end to pseudobulb, 319.6 (296.1-343.1), to base of bulb, 430 (399.5-460.6), to excretory pore, 293.7 (270.2-317.2); greatest width of body, 110.4 (108.1-112.8); width of body at level of vulva, 111.6(110.4-112.8); V,44.4\% (42.1-46.6); length and width of eggs, 57.6 (49.3-65.8) x 38.8 (35.2-42.3).

Type host. Adults of Gryllodes laplatae Saussure, 1877 (Orthoptera, Gryllidae).

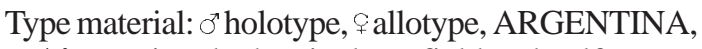
Buenos Aires: Lincoln, horticulture field and golf course (MLP 5072); paratypes same locality: 19 $\sigma, 21$ \&, VI-XI.1999, Reboredo-Camino col. (CHC 270-272). 


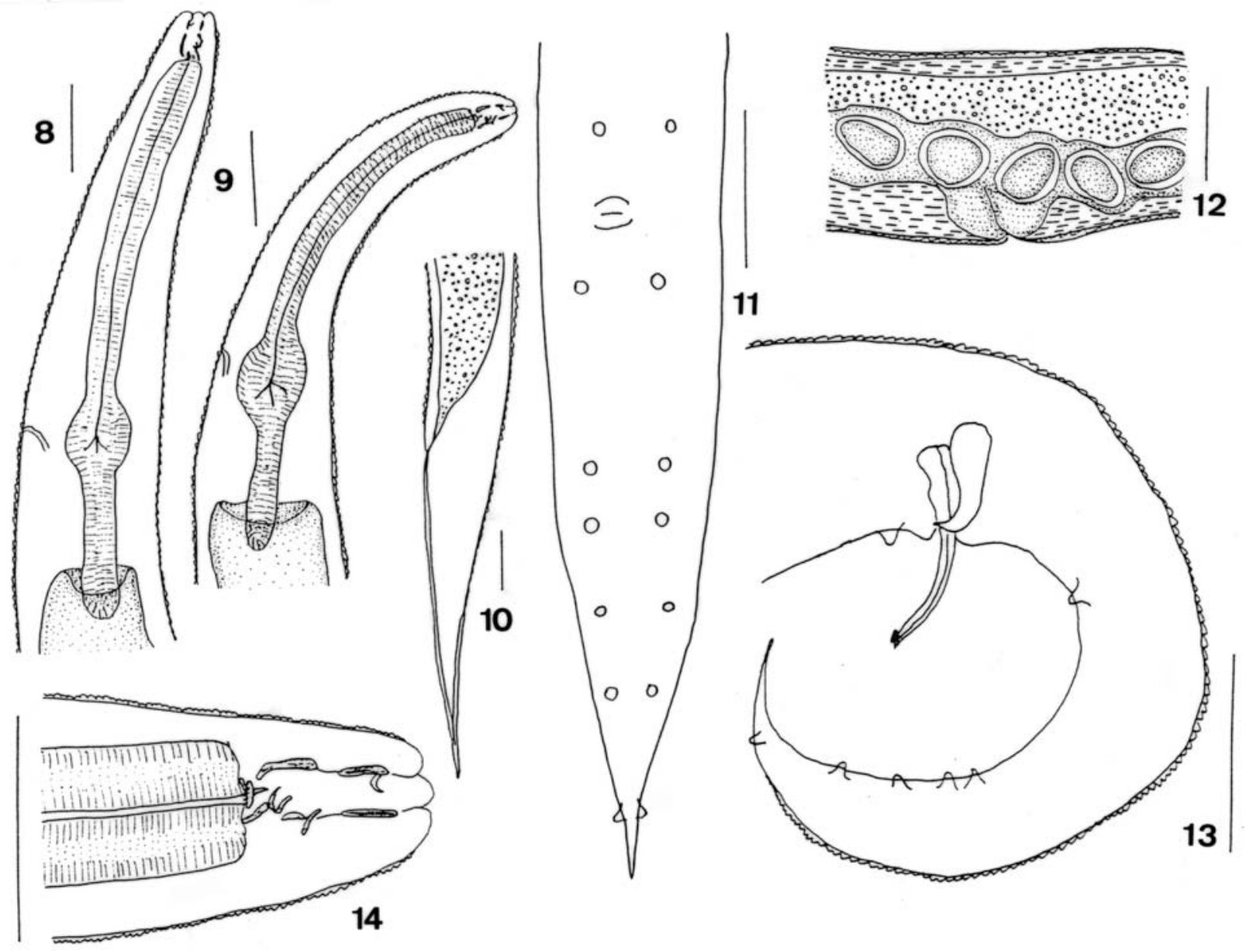

Fig. 8-14. Cephalobium polidentatum sp. nov: 8, anterior end of female, ventral; 9, anterior end of male, ventral; 10, posterior end of female, lateral; 11, posterior end of male, ventral; 12, vagina and uteri with eggs; 13, posterior end of male, lateral; 14, stoma. Bars $50 \mu \mathrm{m}$.

Cephalobium dispar sp. nov.

(Figs. 15-21)

Description. Lip ring divided by six ribs not bifid anteriorly. Stoma long. Glottoid apparatus anisomorphic. Cheilostom and protostom cuticularized, and telostom with several teeth in fan-shaped (fig. 21). Oesophagus long with a valved pseudobulb and basal bulb without valves, not into the anterior end of the intestine (figs. 15, 16). Excretory pore posteriorly at the pseudobulb. Vulva median and protruding. Vagina short, strong and muscular, gonads paired (fig. 19). Male with two parallel spicules, gubernaculum triangular with two wings holding the spicules (fig. 20). Genital papillae in seven pairs (fig. 18): one pair preanal and six pairs postanal, which two pairs near the anus, three pairs grouped and one pair at the base of the tail. Bursa absent. Tail appendage thin (fig.17).

Male $(\mathrm{n}=18)$ : body length, $3,077(2,944-3,210)$; width of the head at level of lip ring, 20 (18.9-21.2); stoma length, 38.8 (37.6-39.9), width, 8.3 (7.1-9.4); distance from anterior end to pseudobulb, 331.3 (321.9-340.7), to base of bulb, 435.9 (423-448), to excretory pore, 329 (293.7364.2); greatest width of body, 77.5 (65.8-89.3); width of body at level of anus, 56.4 (51.7-61.1); spicules length, 69.3 (63.4-75.2); gubernaculum length, 37.6 (32.9-42.3); tail length, 70.3 (65.3-72.6).
Female $(n=21)$ : body length, 4,265 $(4,210-4,320)$; width of head at level of lip ring, 24.7 (23.5-25.8); stoma length, 36.4 (35.2-37.6), width, 10.6 (9.4-11.7); distance from anterior end to pseudobulb, 424.3 (411.2-437.1), to base of bulb, 554.6 (531.1-578.1), to excretory pore, 458.2 (434.7-481.7); greatest width of body, 121 (117.5-124.5); width of body at level of vulva, 133.9 (131.6-136.3); V, $48.5 \%$ (48.4-48.6); length and width of eggs, 76.4 (75.277.5) x 44.6 (42.3-47).

Type host. Adults of Gryllodes laplatae Saussure, 1877 (Orthoptera, Gryllidae).

Type material: ${ }^{t}$ holotype, $\subsetneq$ allotype, ARGENTINA, Buenos Aires: La Plata, horticulture field Gorina, (MLP 5073); paratypes same locality: 17 of, 20 \&, VI-XI.1999, Reboredo-Camino col. (CHC 273-275).

Remarks. Cephalobium laplata, C. polidentatum and $C$. dispar are similar to other species, that have the base of stoma armated with a great tooth. Cephalobium laplata differs by having cheilostom with a dorsal unmovable tooth, and telostom with three ventral small teeth and two ventral movable claw teeth projected into the lumen of the stoma; gubernaculum triangular and with five pairs of postanal papillae. Cephalobium polidentatum is distinguished by cheilostom with a 


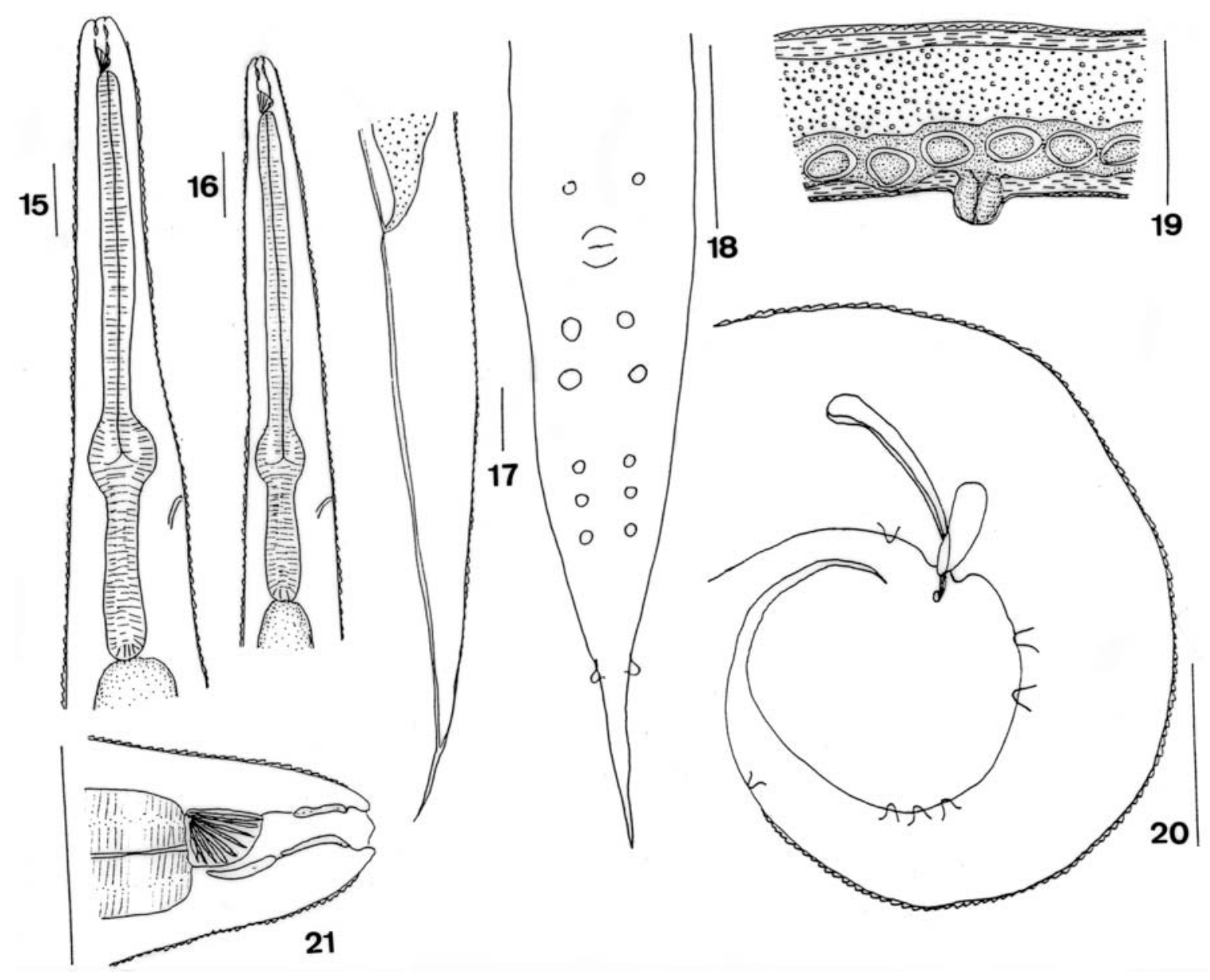

Fig. 15-21. Cephalobium dispar sp. nov: 15, anterior end of female, ventral; 16, anterior end of male, ventral; 17, posterior end of female, lateral; 18, posterior end of male, ventral; 19, vagina and uteri with eggs; 20, posterior end of male, lateral; 21 , stoma. Bars $50 \mu \mathrm{m}$.

movable ventral tooth, prostom with four dorsal movable teeth and telostom with three teeth projected into the lumen of the stoma; gubernaculum triangular with projections; one pair preanal and six postanal papillae. Cephalobium dispar is characterized by having telostom with several fan-shaped teeth; gubernaculum triangular with two wings around the spicules; and one pair preanal and six postanal papillae.

The type species $C$. microbivorum can be distinguished by the number of genital papillae, one pair preanal and five pairs postanal; C. microvata differs by the number and arrangement of genital papillae in the male, one pair preanal and five pairs postanal. Male of $C$. nitidum can be separated by one pair preanal and six irregular pairs of postanal papillae; C. montanum differs in having one pair preanal and four pairs postanal papillae in the male; $C$. bidentatum is distinguished by six pairs of postanal papillae, there is no preanal one.

\section{REFERENCES}

Artigas, P. 1929. Uma nova espécie de nematoideo do gênero Cephalobium Cobb, 1920. Boletim Biológico, São Paulo, 4:81-84.

Camino, N. B. \& Reboredo, G. R. 2000. Nueva especie de Cephalobium (Rhabditida, Diplogasteridae) parásito de ninfas de Gryllodes laplatae (Orthoptera, Gryllidae) en la Argentina. Iheringia, Sér. Zool., Porto Alegre, (89):183-186.

СовB, N. A. 1920. One hundred new nemas (type species of 100 new genera). Contributions to a Science of Nematology, Baltimore, 1:217-343.

PoINAR, G. O., JR. 1975. Entomogenous nematodes. A manual and host list of insect-nematode associations. Leiden, E. J. Brill. 317 p.

RaO, N. P. \& RaO, J. V. 1965. A description of the new species of the genus Cephalobium Cobb, 1920 with comments on other species of the genus. Zoologischer Anzeiger, Bonn, 175:360-364.

Saussure, H. DE. 1877. Melanges Orthopterologiques II fasc. 5, Gryllidae. Mémoires de la Societé de Physique et d'Histoire Naturelle de Genève, Genève, 25:1-352.

Spiridonov, S. E. \& Van Luc, P. 1994. Cephalobium montanum sp. n. (Rhabditida: Cephalobiidae) from the hind gut of the cricket Teleogryllus derelictus Gorochov in Vietnam. Russian Journal of Nematology, Moscow, 2:55-59. 